\title{
Radiation knowledge and perception of referral practice among radiologists and radiographers compared with referring clinicians
}

\author{
Lars Borgen • Erling Stranden
}

Received: 22 February 2014 / Revised: 26 June 2014 / Accepted: 3 July 2014 / Published online: 28 August 2014

(C) The Author(s) 2014. This article is published with open access at Springerlink.com

\begin{abstract}
Objectives To explore if the perception of radiologists and radiographers on referral practice differs from that of referring clinicians, and to see if knowledge of radiation issues and referral guidelines differ between these groups.

Methods A questionnaire was handed out to 46 radiologists and 36 radiographers in Norway. Findings were compared to corresponding results from a similar already published study on clinicians. Questions dealt with referrals unlikely to affect treatment as well as respondents' radiation and referral guideline knowledge.

Results Radiographers estimated the highest proportion of referrals most unlikely to affect treatment (median $20 \%$ ) in comparison to radiologists $(10 \%)$ and clinicians $(5 \%)$. Lack of time, compensating for limited clinical examination and patient expectations were rated as more important reasons for such referrals by radiologists than by clinicians. Radiologists and radiographers possessed significantly better radiation knowledge than clinicians, and were more familiar with referral guidelines.

Conclusions The perception of radiologists and radiographers differs from that of clinicians, concerning the use of imaging most unlikely to affect treatment, and the reasons for such referrals. Radiologists and radiographers possess better radiation knowledge than referring clinicians, but all groups have a potential in improving their radiation protection knowledge.
\end{abstract}

\footnotetext{
L. Borgen $(\bowtie)$

Department of Radiology, Drammen Hospital, Dronning gaten 28, 3004 Drammen, Norway

e-mail: lars.borgen@vestreviken.no

L. Borgen $\cdot$ E. Stranden

Faculty of Health, Buskerud and Vestfold University College,

Grønland 58, 3045 Drammen, Norway
}

Main Messages

- Radiographers estimated the highest proportion of referrals most unlikely to affect treatment.

- Radiologists rated "getting the patient discharged" as an important reason for such referrals.

- Radiologists and radiographers possess significantly better radiation knowledge than clinicians.

Keywords Radiation protection · Education · Referral and consultation $\cdot$ Questionnaire $\cdot$ Diagnostic imaging

\section{Introduction}

A rapid increase in the volume of medical imaging in recent decades has raised medical, health economic and radiation protection concerns. Imaging overuse and significant volumes of unjustified imaging have been described by several authors $[1,2]$. Hence, radiation protection and strengthening of the justification process are important issues of today's radiology [3, 4].

When exploring unjustified imaging and designing efforts to improve the justification process, a relevant question would be if radiologists and radiographers on one side, and clinicians on the other side, have the same understanding of today's referral practice. To what extent are today's practices considered justified on "each side of the table", and are radiation doses weighted equally?

Good clinical practice relies on adequate imaging reports, which in turn is based on diagnostically acceptable images. Performing relevant image acquisitions depends on sufficient referral information. The radiographer needs to know what to visualise and the radiologist what to look for. In this respective, a lack of mutual understanding on clinical indications and motivations for referring could threaten the quality of radiology and clinical practice. 
Several articles have detected scarce radiation knowledge and unawareness of referral guidelines among clinicians [5-9]. These facts underpin the important role of radiologists and radiographers as gatekeepers in the justification process. Hence, radiation and, to some extent, referral guideline knowledge of radiologists and radiographers needs to be sufficient.

Accordingly, the purpose of this study was to see if the perception of radiologists and radiographers on referral practice differs from that of referring clinicians. We also wanted to explore the radiation and referral guideline knowledge of radiologists and radiographers, and to compare this to formerly published findings on referral clinicians.

\section{Material and methods}

In the present study, radiologists and radiographers filled in an anonymous questionnaire. The study did not require approval from a research ethics committee. In a previous paper, results from a corresponding questionnaire handed out to referring clinicians were reported [6].

Our questionnaire was based on literature review, a pilot study of six respondents and individual interviews with four respondents to test face validity. The questionnaire was handed out to respondents during internal meetings at three different hospitals, at national, regional and local levels respectively. All respondents attending the actual meetings were asked to fill in the questionnaire, which took about $15 \mathrm{~min}$. They were not informed about the questionnaire session in advance. The first author supervised these sessions to ensure unaided answers.

The questions concerned, in this order: respondents' age and gender, their weighting of (six-point scale) radiation dose and four other factors when patients are being referred for imaging, whether they knew of (yes/no) and had used (yes/no) referral guidelines [10], if they received referrals for imaging (radiologists and radiographers)/referred for imaging (clinicians) that most unlikely would affect treatment (yes/no), their approximate rate of such referrals $(1,5,10$, 20 or $50 \%$ ) and their rated importance of six listed reasons for such referrals (four-point scale).

The questions exploring referral practice were phrased slightly differently for radiologists and radiographers compared with clinicians [6]. For instance, radiologists and radiographers were asked "Why do you think patients are referred to your department for imaging, when imaging is most unlikely to affect treatment?", while clinicians were asked "What are your reasons for referring when imaging is most unlikely to affect treatment?". Also, there were some variations in demographic questions. Except these differences, the questionnaire was organised and phrased identically for all respondent groups.
We also asked about the effective dose (in equivalent number of chest X-rays) from 12 imaging procedures, including radiography, fluoroscopy, multislice computed tomography (MSCT), magnetic resonance imaging (MRI) and ultrasound. Respondents then had to rank the contribution of medical imaging to the mean effective dose for a Norwegian, compared with that of radon in homes, background gamma radiation, pollution from Sellafield in England and food pollution from the Chernobyl nuclear plant accident. Finally, we explored respondents' knowledge of deterministic and stochastic radiation effects. Except demographic questions, the total number of questions was ten (please see "Appendix").

A total radiation knowledge score was constructed, ranging from 0 to 71 . More detailed information on the questionnaire and the score system can be found in the earlier publication by Borgen et al. [6].

For categorical data, Kruskal-Wallis, Mann-Whitney $U$ and chi-squared tests were used as appropriate (see "Results"). Multiple linear regression analysis was used to examine factors that could influence radiation knowledge. Data were analysed using SPSS (version 16; SPSS, Chicago, IL, USA). A twotailed $p<0.05$ was accepted as statistically significant.

\section{Results}

All invited radiologists $(n=46)$, radiographers $(n=36)$ participated in the study. In the previous study [6], 213 clinicians participated. The mean age of radiographers was 39.7 years (SD 9.6), radiologists 43.8 years (SD 9.8) and clinicians 44.8 (SD 9.9) years. Female percentage was higher among radiographers $(73.5 \%)$ and radiologists $(46.7 \%)$ compared with clinicians $(23.5 \%)$. Mean number of years of working experience for radiologists was 12.2 (SD 9.6) and for radiographers 12.3 (SD8.9). Corresponding data for clinicians was not obtained.

\section{Perception of referral practice}

We found that $93.5 \%$ of the radiologists and $91.7 \%$ of the radiographers received referrals to imaging most unlikely to affect treatment, while $77.0 \%$ of the referral clinicians admitted such referrals in their own practice ( $p=0.008$, chi-squared test). Radiographers estimated the highest proportion of such referrals (median $20 \%$ ) in comparison to radiologists (10\%) and clinicians $(5 \%)(p<0.001$, chi-squared test).

When rating reasons for referrals that were most unlikely to affect treatment (Table 1), "lack of time/getting the patient discharged" was rated more important by radiologists and radiographers than by referring clinicians $(p<0.001)$. The difference was significant between radiographers and clinicians $(p<0.001)$ and between radiologist and clinicians 
Table 1 Median score (interquartile range) for what radiologists and radiographers consider the most important reasons for patients being referred to examinations most unlikely to affect treatment, and clinicians' own reasons for referring patients to such imaging

\begin{tabular}{lllllll}
\hline & $\begin{array}{l}\text { Patient } \\
\text { expectations }\end{array}$ & $\begin{array}{l}\text { Give the patient } \\
\text { the feeling of being } \\
\text { taken seriously }\end{array}$ & $\begin{array}{l}\text { Lack of time, "get the } \\
\text { patient out of the office", } \\
\text { discharge the patient }\end{array}$ & $\begin{array}{l}\text { Expectations } \\
\text { of relatives }\end{array}$ & $\begin{array}{l}\text { Compensate for } \\
\text { insufficient clinical } \\
\text { examination }\end{array}$ & $\begin{array}{l}\text { Normal findings } \\
\text { will reassure the } \\
\text { patient }\end{array}$ \\
\hline Radiologists & $2.0(2.0)$ & $2.0(1.0)$ & $2.0(2.0)$ & $3.0(1.0)$ & $2.0(2.0)$ & $2.0(2.0)$ \\
Radiographers & $1.0(1.0)$ & $1.0(1.0)$ & $3.0(2.0)$ & $2.0(2.0)$ & $2.0(2.0)$ & $2.0(2.0)$ \\
Clinicians [6] & $3.0(1.0)$ & $2.0(1.0)$ & $4.0(1.0)$ & $3.0(1.0)$ & $4.0(1.0)$ & $2.0(2.0)$ \\
\hline
\end{tabular}

$1=$ very important, $4=$ not important

$(p<0.001)$. "To compensate for limited clinical examination" was rated more important by radiologists and radiographers compared with referring clinicians $(p<0.001)$. Again, the difference between radiologists and clinicians $(p<0.001)$ and between radiographers and clinicians $(p<0.001)$ was significant. Expectations of patients were rated as more important by radiographers than by the two other groups $(p<0.001)$. Here, there was a significant difference between radiographers and clinicians $(p<0.001)$ and between radiographers and radiologists ( $p=0.009$ ). The $p$ values were calculated by Kruskal Wallis test and post hoc tests with Bonferroni adjusted Mann-Whitney $U$ tests.

\section{Radiation knowledge}

Radiologists and radiographers possessed significantly better radiation knowledge than clinicians, $p<0.001$, multiple linear regression analysis (Table 2).

\section{Weighing of radiation dose}

Radiographers weighted radiation dose as more important than radiologists and clinicians ( $p=0.03$, Kruskal Wallis test) (Fig. 1). Post hoc Mann-Whitney $U$ test showed significant difference between radiographs compared with radiologists and clinicians $(p=0.012)$.

\section{Use of referral guidelines}

More radiologists than radiographers and referring clinicians knew of and had used referral guidelines (Table 3). A larger

Table 2 Total radiation knowledge score by respondent group

\begin{tabular}{llll}
\hline & Mean & $n$ & Std. deviation \\
\hline Radiologists & 41.1 & 46 & 9.2 \\
Radiographers & 38.2 & 36 & 7.6 \\
Clinicians 6] & 30.4 & 213 & 8.4 \\
\hline
\end{tabular}

Mean score was significantly different among the three respondent groups: $p<0.001$, multiple linear regression analysis proportion of the radiologists who knew of referral guidelines had used them, compared with corresponding proportions of radiographers and clinicians. Further, $34.8 \%$ of all radiologists, $8.3 \%$ of all radiographers and $2.7 \%$ of all referring clinicians were able to state the website of the Norwegian translation of the European Union referral guidelines $(p<0.001$, chi-squared tests $)$.

\section{Discussion}

\section{Discussion of findings}

Our findings indicate that radiologists and radiographers differ from clinicians in their perception of to what extent patients are referred for imaging that is most unlikely to affect treatment, as well as of the reasons for such referrals. There may be several causes of these discrepancies. The digitalisation of radiology may have increased the psychological and physical distance between the referral clinicians, radiologists and radiographers. Electronic referrals and reports, together with decentralised instant image access have reduced the need for physical meetings. The increasing volume of imaging procedures has put radiologists under pressure [11], marginalising consultations between radiologists and clinicians.

The environment of a radiological department differs substantially from a clinical environment. Radiologists without clinical experience, except basic education and training, are becoming more common [12]. The diversity and complexity of a clinical practice, and hence the need for imaging that at first sight might not seem justified, may be hard to grasp for a radiologist with scarce clinical experience, working with a highly selected patient group. This might also explain some of the differences we find concerning what to emphasise when referring.

Inadequate referrals and failing to communicate sufficient information may also explain some of the differences [13-15]. The quality of referrals varies, and several studies have shown that referrals do not adhere to guidelines [16]. Often, they do not include sufficient clinical information for the radiologist and radiographer to assess the degree of justification [13]. 
Fig. 1 Weighting the importance of radiation dose in relation to referrals; $1=$ very important, $6=$ not important. Box-and-whisker plot where the box represents the interquartile range, the middle horizontal line the median and the whiskers the range. Numbered points are outliers

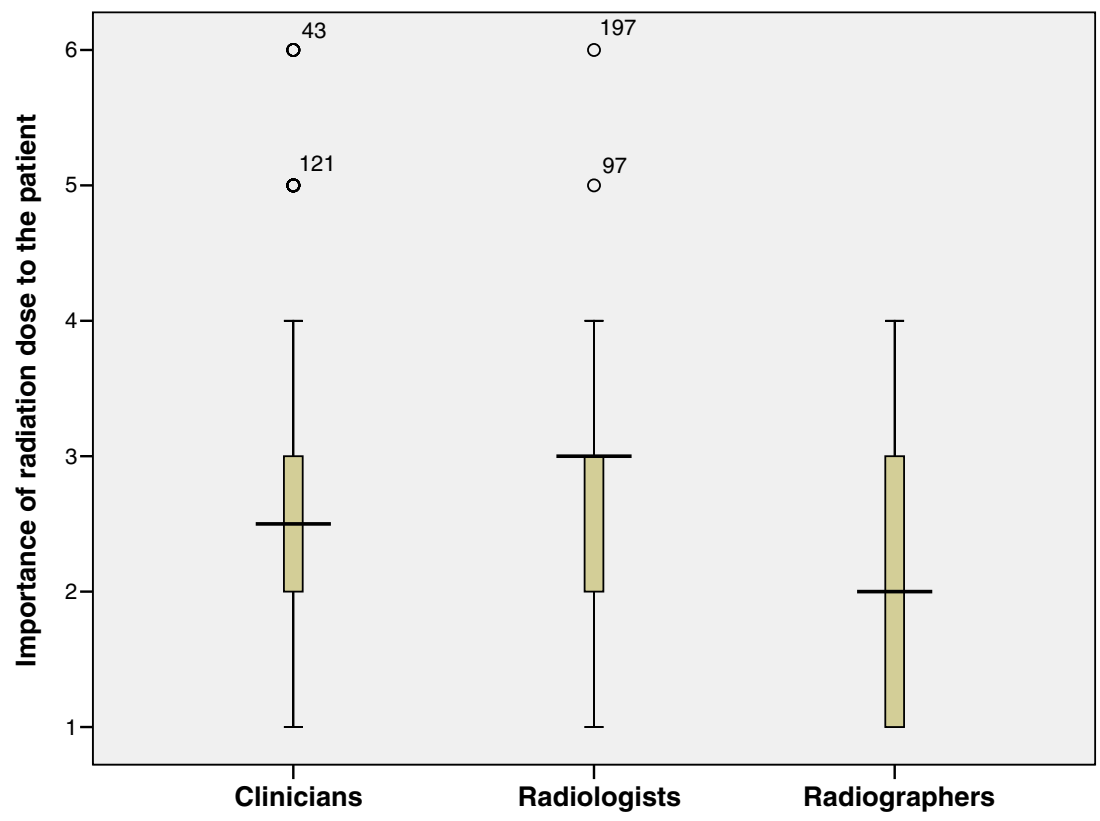

This also might explain some the difference in estimated proportion of referrals most unlikely to affect treatment and reasons for such referrals. Inadequate referrals make it more demanding and time-consuming for the radiologist to prioritise referrals as well as to interpret and report. Hence, the quality of the radiologist's work may suffer from inadequate referrals.

Radiologists are expected to deliver high volumes of high quality image interpretation. The experience of doing a meaningful job is prerequisite for a durable motivation to deliver what is expected. The radiologists express a relatively high proportion of referrals to imaging most unlikely to affect treatment. If this proportion is perceived as somewhat meaningless, this could indirectly threaten the quality of image interpretation and reports.

One could think that clinicians under-report their proportion of referrals for imaging that is most unlikely to affect treatment, to make their referral practice look adequate and justified. The respondents' rates were smaller than some reported rates of unjustified imaging (5-10\% vs $20 \%$ ) [1, 2, 17]. Our respondents may have underestimated their own rates, but the rate of

Table 3 Number and percentage of respondents who knew and used referral guidelines

\begin{tabular}{lll}
\hline & $\begin{array}{l}\text { Knew of referral } \\
\text { guidelines }\end{array}$ & $\begin{array}{l}\text { Had used referral } \\
\text { guidelines }\end{array}$ \\
\hline Radiologists & $39 / 46(84.8 \%)$ & $21 / 46(45.7 \%)$ \\
Radiographers & $14 / 36(38.9 \%)$ & $4 / 36(11.1 \%)$ \\
Clinicians 6] & $123 / 212(58.0 \%)$ & $76 / 213(35.7 \%)$
\end{tabular}

The differences in knowledge and usage were statistically significant, $p<0.001$ and $p=0.003$ respectively, both chi-squared tests unjustified and/or treatment-irrelevant imaging in Norway is not known. However, we believe that avoiding person identifiers reduced such bias, and that our most salient findings reflect substantial differences between respondent groups. Non-clinician respondents in our survey may not have had such motivations, as they did not report on their own practice.

Not surprisingly, radiologists and radiographers possess better radiation knowledge than referring clinicians. Education, as well as the nature of everyday tasks, may explain this difference. Better knowledge hopefully makes radiologists and radiographers more able to evaluate the justification of an examination, compared with referring clinicians. However, the potential for improving radiation knowledge is there for all respondent groups. This complies with Lee et al. [7], who found that radiation knowledge was limited among referring clinicians, as well as among radiologists.

Radiographers weighted radiation dose as more important than radiologists and clinicians. This may be explained by the fact that radiographers in their education and daily work are more closely engaged in the physical and radiation-related aspects of radiology.

Referral guidelines are not widely known among clinicians and only about half of clinicians as well as radiologists who knew of such guidelines used them. This may be explained by a lack of marketing of the Norwegian translation of the EU referral guidelines. The translation was only available online and not as a booklet. There was no regular update. Inadequate implementation of referral guidelines have also been described by other authors $[18,19]$.

This study shows that the considerations of radiologists and radiographers differ from that of the clinicians, concerning the use of imaging most unlikely to affect treatment, and the 
reasons for such referrals. Radiologists and radiographers possess better radiation knowledge than referring clinicians.

To create a common ground and mutual understanding of justification and referral practice, there seems to be a need for improved communication and closer collaboration between radiologists, radiographers and referring clinicians. A common understanding of justification and radiation protection issues could facilitate a meaningful use of the radiological department, mutual confidence as well as sustained high quality radiology.

Strengths and limitations

A $100 \%$ participation rate and unprepared, unaided responses to our questionnaire yielded more valid data than achievable in a postal or e-mail survey. However, the use of questionnaires has inherent limitations, as some answers reflect respondents' subjective opinion. Respondents' self-reporting on their own practice should be interpreted with care. The proportion of referrals to imaging that most likely will not affect treatment may be higher or lower, if investigated with more objective methods. On the other side, the subjective perception on current referral practice is exactly what we wanted to investigate, and knowledge of the differences we find among the respondent groups could be of value when designing efforts to improve the justification process.

We recruited respondents among radiologists and radiographers at institutions from three different hospital levels at morning meetings where residents, junior doctors and senior doctors attend. Clinicians were recruited at such meetings or courses of general interest, and the age of the respondent groups of clinicians corresponded to the age of these groups on a national level $[6,20]$. Age and female percentage among radiologists were 45 years and $44 \%$ on a national level versus 44 years and $47 \%$ in our sample [A. Taraldset, Chief of Statistics, Norwegian Medical Association, pers. commun., 13 May 2014]. For radiographers, corresponding numbers were 44 years and $75 \%$ on a national level and 40 years and $74 \%$ in our sample [A. Petterson, Leader of the Norwegian Society of Radiographers, pers. commun., 13 May 2014]. Thus, we believe that our respondent samples may be fairly comparable to the corresponding groups on a national level.

Conflict of interest There are no conflicts of interest.

Funding source The study was funded by the Department of Radiology, Drammen Hospital, Vestre Viken Health Trust.

The study did not require ethical approval.

Contributorship Lars Borgen developed the idea and the questionnaire, physically handed out the questionnaires, did the statistics and wrote the article. Erling Stranden developed the idea and the questionnaire and took part in writing the article.
Appendix

Table 4 Questions about medical radiation use and radiation protection

\begin{tabular}{|c|c|}
\hline Questions & Response categories \\
\hline $\begin{array}{l}\text { To what extent should the listed criteria } \\
\text { be important when a patient is being } \\
\text { referred for imaging? } \\
\text { Radiation dose to patient } \\
\text { Patient's wish } \\
\text { Impact on diagnosis } \\
\text { Impact on treatment } \\
\text { Impact on patient's future health }\end{array}$ & $\begin{array}{l}\text { Weighting of importance } \\
1-6 ; 1=\text { very important, } \\
6=\text { not important }\end{array}$ \\
\hline $\begin{array}{l}\text { Do you know of imaging referral } \\
\text { guidelines, where referrers can seek } \\
\text { information on which investigations } \\
\text { are indicated for which conditions? }\end{array}$ & Yes/No \\
\hline $\begin{array}{l}\text { Have you ever used such referral } \\
\text { guidelines? }\end{array}$ & Yes/No \\
\hline $\begin{array}{l}\text { Are patients referred to your department } \\
\text { for imaging in cases when you } \\
\text { consider it most unlikely that the } \\
\text { imaging results will affect treatment } \\
\text { of the patient? }\end{array}$ & Yes/No \\
\hline $\begin{array}{l}\text { If yes, what is the proportion of such } \\
\text { referrals among the referrals to your } \\
\text { department (circa)? }\end{array}$ & $\begin{array}{l}1 \%, 5 \%, 10 \%, 20 \% \\
50 \%\end{array}$ \\
\hline $\begin{array}{l}\text { Why do you think patients are referred to } \\
\text { your department for imaging, when } \\
\text { imaging is most unlikely to affect } \\
\text { treatment? Please weight the listed } \\
\text { reasons } \\
\text { Patient expectations }\end{array}$ & $\begin{array}{l}\text { Weighting of importance } \\
1-4 ; 1=\text { very important, } \\
4=\text { not important }\end{array}$ \\
\hline $\begin{array}{l}\text { Give the patient the feeling of being taken } \\
\text { seriously } \\
\text { Lack of time, "get the patient out of the } \\
\text { office", discharge the patient } \\
\text { Expectations from relatives } \\
\text { Compensate for insufficient clinical } \\
\text { examination } \\
\text { Normal findings will reassure the patient }\end{array}$ & \\
\hline $\begin{array}{l}\text { Please estimate the effective dose of the } \\
\text { listed imaging procedures, compared } \\
\text { to a chest X-ray (front and side } \\
\text { projection). Please put a mark, even } \\
\text { if you are uncertain } \\
\text { Cerebral CT }\end{array}$ & $\begin{array}{l}\text { Corresponding numbers of } \\
\text { chest X-rays (front and } \\
\text { side projection); } 0-1 \text {, } \\
1-10,10-50,50-200\end{array}$ \\
\hline Pelvic radiography & \\
\hline Cerebral MRI & \\
\hline Intravenous pyelography & \\
\hline Chest CT & \\
\hline Barium meal fluoroscopy & \\
\hline Barium enema & \\
\hline Abdominal CT & \\
\hline Kidney ultrasound & \\
\hline Thoracic spine radiography & \\
\hline Sinus X-ray & \\
\hline Sinus CT & \\
\hline
\end{tabular}


Table 4 (continued)

\begin{tabular}{ll}
\hline Questions & Response categories \\
\hline $\begin{array}{l}\text { We ask you to rank the contributors to the } \\
\text { mean effective radiation dose for a }\end{array}$ & $\begin{array}{c}\text { Rank, } 1=\text { largest } \\
\text { contributor, } 5=\text { smallest } \\
\text { contributor }\end{array}$ \\
Norwegian patient in 2006 & \\
Medical imaging & \\
Radon in homes & \\
Background gamma radiation & \\
Pollution from Sellafield in England & \\
Pollution from the Chernobyl nuclear & \\
plant accident & \\
Detrimental effects of radiation are divided & Yes/No \\
into deterministic and stochastic effects. & \\
Are you familiar with these terms? If yes, & \\
go to next question & \\
This is a list of potential detrimental effects & Stochastic/Deterministic \\
of radiation. Please mark whether you & \\
think these effects are stochastic or & \\
deterministic (one mark per effect) & \\
Leukaemia & \\
Infertility & \\
Fetus abnormalities & \\
Genetic adverse effects & \\
Cataract & \\
Lung cancer &
\end{tabular}

${ }^{\text {a }}$ Estimates of effective dose were compared with national reference values or - when such values were lacking - with doses measured at the first author's department

Open Access This article is distributed under the terms of the Creative Commons Attribution License which permits any use, distribution, and reproduction in any medium, provided the original author(s) and the source are credited.

\section{References}

1. Almén A, Leitz W, Richter S (2009) National survey on justification of CT examinations in Sweden. Report no. 2009:3. Swedish Radiation Safety Authority, Stockholm

2. Oikarinen H, Merilainen S, Paakko E et al (2009) Unjustified CT examinations in young patients. Eur Radiol 19(5):1161-1165
3. Fazel R, Krumholz HM, Wang Y et al (2009) Exposure to low-dose ionizing radiation from medical imaging procedures. N Engl J Med 361(9):849-857

4. Mettler FA Jr, Bhargavan M, Faulkner K et al (2009) Radiologic and nuclear medicine studies in the United States and worldwide: frequency, radiation dose, and comparison with other radiation sources - 1950-2007. Radiology 253(2):520-531

5. Bautista AB, Burgos A, Nickel BJ et al (2009) Do clinicians use the american college of radiology appropriateness criteria in the management of their patients? AJR Am J Roentgenol 192(6):1581-1585

6. Borgen L, Stranden E, Espeland A (2010) Clinicians' justification of imaging: do radiation issues play a role? Insights Imaging 1(3): 193-200

7. Lee CI, Haims AH, Monico EP et al (2004) Diagnostic CT scans: assessment of patient, physician, and radiologist awareness of radiation dose and possible risks. Radiology 231(2):393-398

8. Mankad K, Bull M (2005) Awareness of 'Making the best use of a department of clinical radiology' amongst physicians. Clin Radiol 60(5):618-619

9. Soye JA, Paterson A (2008) A survey of awareness of radiation dose among health professionals in Northern Ireland. Br J Radiol 81(969): 725-729

10. European Commission (2007) Referral guidelines for Imaging. 362 Luxembourg. Available via http://ec.europa.eu/energy/nuclear/ radioprotection/publication/doc/118_update_en.pdf. Accessed 4 April 2014

11. Bhargavan M, Sunshine JH (2005) Workload of radiologists in the United States in 2002-2003 and trends since 1991-1992. Radiology 236(3):920-931

12. Sistrom CL, Langlotz CP (2005) A framework for improving radiology reporting. J Am Coll Radiol 2(2):159-167

13. Boonn WW, Langlotz CP (2009) Radiologist use of and perceived need for patient data access. J Digit Imaging 22(4): $357-362$

14. Lysdahl KB, Hofmann BM (2009) What causes increasing and unnecessary use of radiological investigations? A survey of radiologists' perceptions. BMC Health Serv Res 9:155

15. Lysdahl KB, Hofmann BM, Espeland A (2010) Radiologists' responses to inadequate referrals. Eur Radiol 20(5):1227-1233

16. Sardanelli F, Quarenghi M, Fausto A et al (2005) How many medical requests for US, body CT, and musculoskeletal MR exams in outpatients are inadequate? Radiol Med 109(3):229-233

17. Royal College of Radiologists Working Party (1992) Influence of the Royal College of Radiologists' guidelines on hospital practice: a multicentre study. BMJ 304:740-743

18. Kumar S, Mankad K, Bhartia B (2007) Awareness of making the best use of a department of clinical radiology amongst physicians in Leeds teaching hospitals, UK. Br J Radiol 80(950):140

19. Matowe L, Ramsay CR, Grimshaw JM et al (2002) Effects of mailed dissemination of the Royal College of Radiologists' guidelines on general practitioner referrals for radiography: a time series analysis. Clin Radiol 57(7):575-578

20. Norwegian Medical Association Web site. Available via www. legeforeningen.no/id/146323. Accessed 4 April 2014 